\title{
A integração das práticas de pesquisa e de ensino e a formação do profissional reflexivo
}

Integration of research and teaching practices and

the training of reflective professionals

Jacques Therrien*

Universidade Federal do Ceará e Universidade Estadual do Ceará

Silvia Maria Nóbrega Therrien**

Universidade Estadual do Ceará

Resumo $\quad 0$ estudo aborda a reflexividade crítica como elemento mediador da integração entre as práticas de pesquisa e de ensino na formação do profissional de educação. Apoiado no parâmetro da pesquisa, como princípio educativo, associado ao pressuposto de que o envolvimento em atividades de pesquisa favorece o desenvolvimento de racionalidades dando suporte a práticas reflexivas capazes de conduzir a aprendizagens mais significativas e autônomas no ensino, o ensaio se propõe: por um lado, a identificar um esquema teórico 'macro' que possa dar suporte à análise de tipos de conhecimento, portanto, de racionalidades que movem a dinâmica da relação teoria-prática na ação educativa; por outro lado, a encontrar esquemas teórico-práticos 'micros' de formação, para a reflexividade, relacionados à prática em contextos de aprendizagem. $\mathrm{O}$ estudo analisa propostas de autores de referência, assim como práticas educativas que dão suporte aos pressupostos enunciados.

PALAVRAS-CHAVE: Reflexividade crítica, Integração pesquisa e ensino, Formação do educador.

Abstract This study approaches critical reflexivity as a mediating element of the integration between research and teaching practices in the training of the education professional. Based on the parameter of research as an educational principle associated to the presupposition that involvement in research activities encourages the development of rationalities that support reflective practices, which lead the most significant and independent learning processes, this essay aims at, on the one hand, identifying "macro" theoretic schemes that may support the analysis of different knowledge types and therefore, the rationalities that affect theory-practice dynamics in education initiatives and on the other hand, finding "micro" theoreticalpractical schemes for reflective training related to the practice in learning contexts. The study analyzes proposals made by reference authors, as well as educational practices that support enunciated presuppositions.

KEYWORDS: Critical reflexivity, Research and teaching integration, Educator training. 


\section{Introdução}

Estudos que abordam a reflexividade do profissional de ensino como fundante de uma prática competente, em contexto de ação situada, foram objeto de análise de muitos autores com abordagens diferenciadas, desde os trabalhos desenvolvidos por Donald Schon nos anos 1980 e anteriormente por John Dewey na década de 1940. Tratando-se de um paradigma complexo, continua apresentando zonas cinzentas de compreensão, quando se focaliza a formação para essa prática reflexiva, em contexto que integra a relação dialética entre ensino e pesquisa na docência universitária. $\mathrm{O}$ axioma, segundo o qual a pesquisa produz conhecimento e o ensino produz aprendizagem a este conhecimento, expõe o pressuposto da prática reflexiva crítica e transformadora como elemento articulador dessa relação, o que conduz a formular indagações sobre os elementos e mecanismos que viabilizam essa dimensão.

A compreensão da pesquisa, como princípio educativo (DEMO, 1999), inclui na sua essência a concepção da produção de conhecimento como produção de aprendizagem, tendo a reflexividade situada como mecanismo de mediação. Que reflexividade é essa e que elementos a constituem? Como esta se manifesta na gestão da prática educativa? São indagações ainda pouco esclarecidas desse paradigma, as quais remetem às condições necessárias para a formação do profissional de docência nas instituições de ensino superior.

O enfoque de uma prática educativa, que reflete a integração ensino e pesquisa, bem como o significado dessa práxis, no chão da sala de aula, em relação à aprendizagem, e aos saberes, resultam de preocupações de longa data oriundas de questionamentos sobre experiência no ensino, tanto em disciplinas de metodologia de pesquisa, quanto em orientações de trabalhos científicos, monografias, dissertações e teses, ainda em atividades de grupos de pesquisa que, muitas vezes, resultaram em produção científica sobre a temática. Essa trajetória gerou o desafio de identificar esquemas reflexivos que possam contribuir para a compreensão do movimento de integração ensino e pesquisa na prática docente cotidiana.

A formação para a adoção de uma 'postura investigativa' pelo educador tem suporte em referenciais que contribuem para a busca da legitimação de uma prática educativa de ensino integrado à pesquisa, e vice-versa. Fundamentada em esquemas cognitivos e empíricos como marcos de um pensamento reflexivocrítico.

As principais contribuições teóricas, encontradas na literatura de referência sobre a prática docente articulada à produção da pesquisa, são provenientes de textos produzidos por Sacristán (1999), seguidos de autores como Arendt (1984), Demo (1999), Libâneo (2002), Habermas (1997) Perrenoud, et al (2001) entre outros. A reflexividade relacionada à prática da pesquisa encontra igualmente fundamentos nos trabalhos de outros autores como Zeichner (1993), André (2001), Ludke, et al (2001), Pimenta (2002) dedicados a evidenciar esta relação e a importância de sua contribuição para a formação docente. 
Como expressão da pergunta fundamental que move este ensaio, recorremos ao pressuposto de que o envolvimento sistemático, em atividades de pesquisa, favorece o desenvolvimento de racionalidades que dão suporte a práticas reflexivas, geradoras de questionamentos e argumentações, que conduzem à melhor compreensão dos significados dos saberes objetos do ensino, portanto, a aprendizagens mais significativas e autônomas (ZEICHNER, 1993).

Este ensaio se propõe, por um lado, a identificar um esquema teórico 'macro' que possa dar suporte à compreensão da relação teoria-prática na ação educativa, viabilizando a análise dos tipos de conhecimentos, portanto, das racionalidades que movem essa dinâmica; por outro lado, encontramos esquemas teórico-práticos 'micros' de reflexividade relacionados à nossa ação/prática em contexto institucional: nas disciplinas ministradas, nas atividades escolares, nos diversos espaços e tempos de aprendizagem, como nos grupos de pesquisa, orientações aos alunos, elaboração de monografia, de trabalhos de TCC, e também nos projetos de investigação, entre outros.

Os esquemas 'macro e micro' de reflexividade, mostrados como quadro de fundo neste trabalho, possuem como elo uma teia de mediação, um movimento e uma dinâmica. Abordamos a reflexividade como um método que, segundo Sacristán (1999), se utiliza ou que se pode utilizar para alcançar níveis mais altos de racionalidade na prática.

Asindagaçõesenunciadasnestaintrodução procuram captaraconcepção e a elaboração de um argumento constituinte de um fenômeno complexo que se encontra em movimento. Dito de outra forma, o desafio de desenvolvermos uma 'postura investigativa' de reflexividade crítica, nos sujeitos da aprendizagem, por meio da integração ensino e pesquisa, se ancora e se enriquece nos referenciais teóricos de apoio (contexto macro) e igualmente nas possibilidades reais do trabalho docente (contexto micro-metodologias e práticas).

\section{Reflexão sobre a prática: todo pensamento sobre a prática é reflexão?}

A busca de um sentido para o que fazemos na qualidade de educadores docentes, no ensino superior, nos leva a reivindicar condições tanto para o aprofundamento de questões, sobretudo teóricas, inerentes a nossa prática pedagógica, quanto para nos distanciar um pouco dessa e pensar sobre ela. Acreditamos saber o 'que' e 'como' fazemos, mas devemos procurar sempre os 'porquês', ou seja, as razões desse fazer, com a intenção de melhoria e legitimação da prática que desenvolvemos. Daí nos ancoramos, inicialmente, no que nos diz Arendt (1984, p. 107) "Todo pensamento nasce da experiência, mas nenhuma experiência obtém algum sentido ou coerência sem ter sido submetida antes as operações da imaginação ou do pensar". E complementa: "Pensar sobre o que se faz é uma manifestação da condição reflexiva das pessoas em todas as suas atividades conscientes" (Ibidem, 1984, p. 93). 
Todo ser humano é reflexivo, todos pensamos sobre o que fazemos. Refletir é voltar, pensar sobre si mesmo. Há sempre, no entanto, uma substantiva diferença e graus diversos de profundidade entre as reflexões que os seres humanos produzem (LIBÂNEO, 2002, p. 138). Partimos do pressuposto de que todo ser humano é dotado de reflexividade; entendemos, também, que nem toda reflexão é do mesmo nível, como anota Giroux (1997, p. 15), quando nos diz que "o enfoque reflexivo finda naquilo que ignora". O professor, portanto, não deve limitar seu mundo de reflexão e ação somente ao momento presente da sala de aula. A necessidade de transcender esse nível de reflexão, que se limita a uma visão técnica da realidade imediata, aponta para um trabalho de cunho intelectual e formativo que requer um saber fazer (TARDIF, 2002; LIBÂNEO, 2002).

Situar o cerne do problema em foco, no contexto da gestão da prática educativa, conduz a indagar que racionalidade articula os saberes e conhecimentos que fundamentam essa práxis, portanto, que reflexividade dinamiza e dá forma à articulação desses saberes? Em situação de ensino, caracterizada pelas relações intersubjetivas de ação comunicativa entre um sujeito mediador e sujeitos aprendizes, a reflexão transcende o sujeito individual, transpondo-o para uma dimensão social e coletiva que também não exclui sua individuação.

A reflexão crítica e transformadora da ação comunicativa e dialógica da docência pressupõe, dos sujeitos participantes, atitude de busca de entendimentos econsensosvoltados paraa produção desentidos, significadosesaberesqueatingem suas identidades no horizonte de uma emancipação social. As racionalidades, que perpassam a reflexividade são diversas. Com efeito, como entender e caracterizar a reflexividade, necessária à gestão da prática educativa de um sujeito mediador de aprendizagem aos saberes e conhecimentos? De que reflexividade estamos falando?

\section{A ação pedagógica implica reflexividade: que reflexividade} é essa?

O conceito e as dimensões da reflexão, assim como a definição de três níveis de reflexividade que caracterizam os agentes da educação, expressos por Sacristán (1999), oferecem materiais importantes para adentrarmos questões que contribuem para a compreensão da nossa prática educativa, de ensino e de pesquisa. Senão vejamos.

A reflexão, na concepção de Sacristán (1999, p. 45), é uma exigência que nos impomos, a nós mesmos e aos demais, em relação aos motivos que orientam a nossa ação, para que seja contrastada com as normas de comportamento aceitável. Para o autor, há duas dimensões de reflexão e três níveis de reflexividade. Quanto às duas dimensões: "[...] a primeira, que supõe o exercício da capacidade cognitiva para analisar, esboçar e avaliar as ações em contextos determinados, e a segunda, a que supõe sua utilidade moral para discernir o valor e o significado que possuem". 
Ficam evidenciadas, nessas dimensões, de um lado, a autonomia do profissional de docência para caminhar em um sentido ou em outro; do outro, suas responsabilidades pessoais, sociais e éticas na decisão que venha a tomar e que implica o 'outro' sujeito social. Quando desenvolvemos nossa prática pedagógica em 'contextos institucionalizados de ação educativa' na universidade, em disciplinas, reuniões, comunicações cientificas, na interação com outros sujeitos, pares e alunos, o fazemos não só em origem nos nossos conhecimentos, crenças e racionalidades, mas também com o entendimento de que esses elementos pessoais também são sociais, porque são, de certa forma, resultados de vivências compartilhadas socialmente. Admitir, refletir, dialogar com esse pensamento pessoal e compartilhado, na concepção de Sacristán (1999, p. 105), "é a primeira manifestação da reflexividade, mecanismo essencial para dotar as práticas de racionalidade, tornando os agentes conscientes das suposições que as influenciam". Assim, a reflexividade, para o autor, precisa unir as duas referidas dimensões de reflexão, evidenciando o poder da reflexão como mecanismo de aperfeiçoamento, tanto do pensamento quanto da ação, do saber fazer, no caso, o do docente.

Para Sacristán (1999), o primeiro nível da reflexividade refere-se aos componentes cognoscitivos da ação: o distanciamento que o agente (sujeito) pode fazer de sua prática (objeto), para pensar sobre ela. Para o autor, é como se fora o primeiro passo de "teorizar" sobre a ação entendida como a prática consolidada. De tal modo, a reflexividade de primeiro nível traz uma dimensão inerente à ação. É uma reflexibilidade de tipo imediato que tem origem na experiência, lugar onde as primeiras impressões podem caminhar para a compreensão, além das evidências aparentes, que se encontram relacionadas diretamente ao senso comum. Nessa etapa, o compartilhar com os outros, como professores e alunos, enriquece esse caminhar, na medida em que os contextos de interpretações alimentam uma nova compreensão, mas com limitações.

Sacristán (1999, p. 129) lembra, no entanto, que a reflexibilidade de primeiro nível é importante e necessária, porque dela dependem as determinações do senso comum para poder operar. Para ele, no entanto, "essa reflexibilidade será esgotada, ou caminhara mais lentamente, ao ficar relegada a seus próprios recursos e as suas próprias invenções, se a do segundo nível não lhe oferecer outros materiais."

É, nesse espaço, que entra o conhecimento disciplinar ou cientifico, os saberes docentes (TARDIF, 2002) como fornecedores legitimados dos dados imbuídos de outras visões e compreensões da educação, os quais podem permitir aos sujeitos da educação a passagem ou ascensão do primeiro para o segundo nível de reflexividade. Mais concretamente, o surgimento do segundo nível de reflexividade, no entendimento de Sacristán (1999, p. 177), ocorre

[...] como uma racionalidade mais depurada e elaborada, que se situa na interação recíproca entre o conhecimento cientifico e o conhecimento pessoal ou o compartilhado, sendo estes ligados à ação e às práticas sociais que ficarão mediadas por aquele. 
Ainda no entendimento do autor,

[...] a reflexividade com a ciência dá o tom que diferencia um modelo de relação positivista entre a teoria e a prática, e outro, no qual a ciência é incorporada devido à sua penetração nos processos de reflexão-ação. (SACRISTÁN, 1999, p. 117)

Com amparo nessa lógica de pensamento, Sacristán (1999) deixa claro que existem certas misturas e alguma continuidade entre o senso comum e a ciência e vice-versa. Resta claro no seu discurso a idéia de que, na sociedade do conhecimento, os fenômenos relacionados com a reflexividade de segundo nível são essenciais para compreender e orientar a educação e, nesse sentido, a prática docente.

Quando o autor adentra a reflexividade de terceiro nível, registrada sob o titulo de "pensar como e sobre quem pensamos a educação", ele resume sua compreensão, ao referir que,

\begin{abstract}
[...] a educação para os agentes que a realizam pressupõe o desenvolvimento de processos reflexivos de primeiro nível inseridos no contexto de seu senso comum e das instituições dentro das quais operam. Na modernidade, instaura-se, com toda a vigência, o principio de que esses processos, assim como o projeto de educação que estimula o sistema escolar, devem ser dirigidos racionalmente e de forma científica, desenvolvendo, assim, um âmbito de reflexividade de segundo nível que enriquece o primeiro. Pensar quais as características que ambos os tipos de reflexividade possuem é desenvolver outra de terceiro nível. (Ibidem, p. 131)
\end{abstract}

Ou seja, precisamos entender o que realizamos. Fazemos parte de uma realidade educacional que queremos entender e, neste sentido, devemos ser conscientes de nossas aportações como sujeitos que fazem teoria em contextos de educação que são sociais: "o domínio da teoria não pode ser desligado das práticas sociais" (Ibidem, p. 25).

É, neste nível, que se torna mais evidente a complexidade da reflexividade constituinte do sujeito que a concepção gramsciana qualificou de 'intelectual orgânico' e que, na sociedade contemporânea, deveria ser referencial do perfil do profissional 'objeto' da formação universitária. A linguagem como elemento de comunicação e de dialogicidade, tanto nos contextos educacionais como da vida cotidiana, revela um espaço importante e fértil como instrumento e fator de entendimento e troca, nos encontros intersubjetivos, essenciais à constituição da identidade de cada ser humano. A contribuição de Habermas (1997) com a compreensão de que, a ação humana há de ser analisada na sua composição objetiva/instrumental e/ou ainda subjetiva/comunicativa, além das suas componentes estratégicas, movidas por determinadas intencionalidades, fornece elementos para a compreensão de uma racionalidade movida por essa reflexividade de convergência, que admite o encontro de racionalidades diversas, portanto, de níveis de reflexividade que vão do senso comum à perspectiva da 
ciência. A racionalidade objetiva do mundo sistêmico encontra plenitude junto à racionalidade subjetiva do mundo da vida: a integração de saberes e conhecimentos diversos constituem o cenário de formação de sujeitos profissionais e cidadãos. Da mesma forma, as dimensões da reflexão e os diversos níveis de reflexividade construirão a competência do profissional de nível superior, portanto, ser parte instituída dos seus processos de formação.

Libâneo (2002), em estudo posterior ao de Sacristán, analisa a noção de reflexividade nos campos da Filosofia e da Pedagogia identificando, também, três níveis de reflexividade que conceitua como 'três níveis de significados'; faz, contudo, uma diferenciação entre o primeiro e o segundo nível reconhecidos por Sacristán. Libâneo (2002), identifica o primeiro como consciência dos próprios atos, o pensar sobre si mesmo. A ação, para ele, só vai aparecer na reflexividade de segundo significado, onde a reflexão é entendida "como relação direta entre minha reflexividade e as situações práticas" (LIBÂNEO, 2002). Sacristán (1999), no entanto, refere que a ação cuja origem está na experiência, é uma dimensão inerente à reflexividade.

Na leitura de Libâneo (2002, p. 56-57), é no terceiro significado (nível), que encontramos o que conceitua como reflexão dialética.

"Há uma realidade dada, independente da minha reflexão, mas que pode ser captada pela minha reflexão". Essa realidade ganha sentido com o agir humano, é uma realidade em movimento que necessita da elaboração de uma explicação do real.

Esse autor demonstra também dois tipos básicos e opostos de reflexividade; uma que ele chama de reflexibilidade neoliberal, e outra de reflexividade critica. A primeira tem sua base na racionalidade instrumental, enquanto, no campo oposto, se encontra a reflexividade comunicativa criticoreflexiva e hermenêutica pela busca do sentido e do significado.

A análise de Libâneo, embora siga por caminhos diferenciados se comparada às dimensões da reflexividade relacionadas por Sacristán, proporciona elementos complementares. No caso da ação educativa que deve refletir sobre a realidade da educação e sobre os efeitos que ela produz nesta, está presente a ação dialética do 'terceiro nível de reflexividade', o que reforça a importância dos agentes da educação serem possuidores de um conhecimento mais depurado, no caso, pela reflexividade de segundo e terceiro níveis.

A contribuição da reflexibilidade, no campo da educação, está em desenvolver uma prática mais apurada para desvelar compreensões dessa área. Como educadores, este seria o lugar, para Sacristán (1999, p. 139), dos especialistas e intelectuais/pesquisadores. Lembra o autor, com relação aos 'atores' da educação, que como a objetividade do conhecimento não é independente dos valores no momento de entender ou de esclarecer a prática, a formação destes intelectuais/ pesquisadores deve pressupor o reconhecimento das implicações de sua prática na construção da realidade. 


\section{Reflexividade como mediação de integração ensino e pesquisa na prática pedagógica universitária: contribuições metodológicas e práticas}

O desenvolvimento da reflexividade pela integração do ensino e da pesquisa constitui importante fator de mediação nos processos de formação profissional e cidadã. Reconhecemos que não é só por meio da pesquisa que o professor pode se tornar um profissional reflexivo (PERRENOUD et al, 2001), pois a prática reflexiva não é uma metodologia de pesquisa e sequer constitui uma competência adquirida por simples treinamento. $O$ entendimento de que a pesquisa é, importante na formação, principalmente de formadores, posição que já é consenso na literatura, aponta para o desafio de desenvolver uma 'postura investigativa' no educando, como princípio de formação para a reflexividade crítica e transformadora, desafio esse que perpassa as atividades de ensino.

Possibilidades de articulação do ensino e pesquisa na formação docente foram desenvolvidas por André (2005, p. 61) no início do ano 2000, quando indicava como a pesquisa pode se tornar um eixo ou núcleo de um curso, ou seja, que ela integrasse o projeto de formação inicial e continuado da instituição; da mesma forma, a autora aborda o uso da pesquisa como mediação para a aprendizagem. Sugestões, contudo, parecem ainda longe da realidade das universidades e mais ainda das escolas.

$\mathrm{Na}$ área da saúde, em contexto universitário, por exemplo, importantes mudanças ocorreram com os novos projetos pedagógicos propondo a integração de disciplinas em temas mais gerais de pesquisa, nos quais grupos de professores de disciplinas afins se articulam para evitar repetições de conteúdos e desenvolver enfoques metodológicos inspirados na 'aprendizagem baseada em problemas'. Da mesma forma, experiências nossas, no ensino, em disciplinas de metodologia de pesquisa, permitiram identificar contribuições metodológicas e práticas onde a reflexão é potencializada como mediação nas condições para a sua integração com a pesquisa.

\section{As condições para a prática da pesquisa: ilustrando possibilidades de integração com o ensino}

A reflexividade nos permite fazer um distanciamento da nossa prática pedagógica, para podermos perceber com maior clareza como organizamos as tarefas e as atividades, nas quais estão inseridos os conteúdos e as habilidades que queremos trabalhar com os nossos alunos. Como organizamos nossos esquemas para ensinar o que só pode ser aprendido na prática? Como integrar ensino com a pesquisa nesse processo?

A estrutura, na qual organizamos nossa prática de ensino, depende em grande parte de determinações institucionais que estabelecem: carga horária, número de créditos, distribuição das horas e créditos numa estrutura curricular de semestres, dias da semana, turnos, entre outros. Entendemos que, com essa 
estrutura, o planejamento e a organização de esquemas de aprendizagem ficam circunscritos a espaços, tempos, conteúdos e número de alunos, o que exige do docente, não apenas conhecimentos, mas, igualmente, competência para ensinar. São requeridas habilidades para descobrir modalidades de abordagem dos conteúdos, dentro ou fora do contexto escolar, despertando, no aluno, a motivação para aprender a aprender, para aprender a pesquisar. Ademais, sendo o ensino mais do que uma mera interação de professor e aluno, a ecologia da classe constitui um elemento que se deve sempre ter em mente para o planejamento da prática educativa exitosa. Ao domínio dos conteúdos pelo docente se acrescenta o domínio do ofício de artesão, ou seja, da criatividade situada. Sacristán (1999, p. 203) ensina que "entender essa situação e planejá-la para que contribua para determinados propósitos implica um campo de conhecimento mais amplo no qual se atendam a todos os elementos e suas interações".

A reflexão que nos permite identificar e compreender os condicionantes das intervenções educacionais, nos processos de ensino e aprendizagem, viabiliza, ao mesmo tempo, a busca e a análise de alternativas de ação que dão sentido e significado à nossa prática pedagógica no chão da sala de aula. O contexto específico do ensino superior é modelador dos processos de aprendizagem do aluno e dos esquemas nos quais nós professores atuamos com base na realidade que é dada.

É reconhecido o ambiente da sala de aula como espaço caracterizado por circunstâncias e acontecimentos diversos e muitas vezes imprevisíveis, que exigem ação imediata. Quando, no início de um semestre letivo, é apresentada a um grupo de alunos uma nova disciplina com seu programa, sua ementa, os objetivos a serem alcançados, as tarefas a serem realizadas, o tempo para desenvolvê-las, os critérios de avaliação a serem utilizados, a bibliografia a ser consultada..., nos encontramos em situações nas quais podem surgir comportamentos imprevisíveis dos alunos e propostas ou fatos que vão exigir uma decisão imediata do professor, o qual pode optar pela negociação ou não.

Nesse exemplo, tão recorrente em um ambiente de classe, o professor mantém um forte envolvimento pessoal em que a reflexão e a comunicação constituem sua ferramenta mais usual. Essa necessidade imediata de posição não permite a maturação prévia de uma decisão de maior objetividade para agir. Na compreensão de Sacristán (1999), a complexidade desse ambiente (estrutura da prática) pode ser aborda por meio de esquemas práticos subjacentes à ação do professor, como uma força determinante que regula sua prática e a simplifica. Em suas palavras:

Alguns esquemas são relativamente estáveis, reclamados por um principio de autonomia de ordem psicológica no profissional e pelos condicionamentos institucionais e sociais que demandam pautas adaptativas de resposta. Esses esquemas de comportamento profissional estruturam toda a prática docente. (SACRISTÁN, 1999, p. 206) 
Daí o entendimento do autor de que, ao renovar sua prática, a renovação para o docente é uma acomodação de esquemas prévios em virtude da assimilação de outras propostas. Quando introduzimos novas tarefas ou tarefas mais adaptadas, as atividades que estamos propondo são elaboradas com dados prévios (reflexãocrítica), que podem ter surgido da observação da inadequação de determinada tarefa ou simplesmente por visualizamos outra maneira de executá-la, que acreditamos proporcionar os resultados desejados. Professores refazem seus esquemas com base em pequenas adequações relacionadas não só com o conteúdo em si, mas também com o tempo da tarefa, a unidade do semestre, o número de alunos, entre outros.

Quando estabelecemos que o desenvolvimento de uma tarefa, como uma pesquisa bibliográfica, por exemplo, se dê na biblioteca, ou quando a tarefa envolve visita orientada à biblioteca, informando que os alunos devem observar e visitar mais de uma biblioteca, temos que planejar toda a atividade, que vai exigir: a elaboração de um esquema de busca de bibliotecas, contatos com bibliotecários, endereços, horários, preparação do roteiro de visita do que se pretende com a referida tarefa, e qual será a atividade utilizada para sua avaliação.

Esse planejamento leva em consideração que, na atividade de visita, vamos proporcionar aos alunos processos de formação à postura investigativa pela reflexividade necessária para o desenvolvimento das atividades e procedimentos: de consulta de fontes, de descoberta dos elementos que necessitam para encontrar uma obra ou um autor, de adequação do manejo, da busca e da utilização da obra selecionada, de compreensão do funcionamento de uma biblioteca. As práticas investigativas e pedagógicas que perpassam esse simples exemplo levam ao entendimento, pelo aprendiz, da importância da biblioteca para sua formação, para sua profissão e a comunidade em geral, além de preparação do relatório sobre a visita. A diversidade de atividades realizadas proporciona muitas informações e conteúdos de aprendizagens que podem, posteriormente, ser reusados quando da apresentação da tarefa em sala de aula. Aprender uma técnica, pensar sobre ela, expor o pensamento em forma de texto, analisar, chegar a conclusões, são exigências gradativas de complexidade variadas, ocorrentes com o desenvolvimento de tarefas pedagógicas que podem ser analisadas por intermédio do paradigma da epistemologia da prática.

Quando da apresentação, em classe, de um relatório de atividades, por exemplo, uma infinidade de questões e situações pode ser identificada despertando, no aluno, a motivação para nova busca de dados, sua organização, análise e discussão de conclusões; se deverá utilizar para isso uma entrevista, um questionário e/ou outros procedimentos adequados. A teia de indagações e argumentos que se forma, há muito, já iniciou o processo concreto de integração do ensino com a pesquisa, desenvolvendo, no aluno, uma postura crítica e investigativa. A reflexividade foi potencializada como mediação em todo esse processo.

A primeira vista, o desenvolvimento da tarefa de ensino-aprendizagem na Visita orientada à biblioteca se mostra basicamente de forma técnica. $\mathrm{O}$ 
trabalho do professor que, no entanto, inclui sua reflexividade, é posto a prova e a experiência adquirida com o esquema por ele elaborado constitui um novo saber, que poderá favorecer outras práticas integradas de ensino e pesquisa. Adentramos assim, à utilização de esquemas práticos que simplificam a complexidade do processo de ensinar pesquisa, promovendo uma 'postura investigativa' necessária à formação para realidades em constantes transformações.

\section{A modo de conclusões}

A reflexividade estruturante e instituinte do ser humano, portanto, que potencializa e dinamiza processos educacionais de emancipação, é uma reflexividade de mediação na dialética, que articula a dimensão individualizante e socializante de reflexão do sujeito, integrando os três níveis identificados por Sacristán e Libâneo. Embora apontada como necessária à postura e, portanto, à identidade do profissional de educação, mediador nos processos de aprendizagem aos saberes e conhecimento, essa reflexividade é essencialmente aquela que vem constituir o ser humano na plenitude de sua emancipação.

Essa compreensão remete à natureza da reflexividade que estrutura a racionalidade, a qual, por sua vez, move as relações intersubjetivas de ensino aprendizagem. Encontramos, assim, uma fundamentação para compreender a reflexividade fundante do movimento dialético que integra o ensino à pesquisa e vice-versa na produção de conhecimentos e de aprendizagem. Justifica-se a necessáriaposturadoprofissionaldeensinocomointelectual/pesquisadormediador de aprendizagem. Uma posição reflexiva que move sua prática e a formação dos seus aprendizes em contextos cotidianos de vivências que produzem sentidos, significados e saberes novos, porquanto expressam contornos de transformações que a reflexividade crítica proporciona.

\section{Referências}

ANDRÉ, M. Pesquisa, formação e prática docente. In: ANDRÉ, M. (Org.). O papel da pesquisa na formação e na prática dos professores. 4. ed. Campinas: Papirus, 2005 . p. 55-70.

ARENDT, H. La vida del espírito. Barcelona: Paidós, 1984.

DEMO, P. Pesquisa: principio científico e educativo. 6. ed. São Paulo:Cortez, 1999.

GIROUX, H. Os professores como intelectuais: rumo a uma pedagogia crítica da aprendizagem. Porto Alegre: Artes Médicas, 1997.

HABERMAS, J. Teoria de la acción comunicativa: complementos y estúdios prévios. Madrid: Cátedra, 1997.

LIBÂNEO, J. C. Reflexividade e formação de professores: outra oscilação do pensamento pedagógico brasileiro? In: PIMENTA, S. G.; GHEDIN, E. (Org.). Professor reflexivo no Brasil. São Paulo: Cortez, 2002.p. 53-80.

LÜDKE, M. et al. O professor e a pesquisa. Campinas: Papirus, 2001.

PERRENOUD, P.; PAQUAY, L.; ALTET, M.; CHARLIER, E. Formando professores profissionais. Quais estratégias? Quais competências? Porto Alegre: Artmed , 2001. 
PIMENTA, S. G. Professor reflexivo: construindo uma crítica.In: PIMENTA, S. G.; GHEDIN, E. Professor reflexivo no Brasil. São Paulo: Cortez, 2002. p. 17-52.

SACRISTÁN, J. G. Poderes instáveis em educação. Porto Alegre. Artes Médicas, 1999.

TARDIF. M. Saberes docentes e formação profissional. Petrópolis: Vozes, 2002.

BARRETO, M. C. Docência e formação de professores: novos olhares sobre temáticas contemporâneas. Fortaleza: EdUECE, 2010. p. 99-108.

ZEICHNER, K. M. A formação reflexiva de professores: ideias e práticas. Lisboa: Educar, 1993.

* Professor Doutor da Universidade Federal do Ceará e Universidade Estadual do Ceará. Fortaleza, Ceará

- Brasil.

** Professora Doutora da Universidade Estadual do Ceará. Fortaleza, Ceará - Brasil.

\section{Correspondência}

Silvia Maria Nóbrega Therrien - Universidade Estadual do Ceará, Centro de Ciências da Saúde, Departamento de Saúde Pública. Avenida Paranjana, 1.700 Campus do Itaperi, Itaperi, CEP: 60740-000 - Fortaleza, Ceará - Brasil.

E-mail: jacques.therrien@pq.cnpq.br - silnth@terra.com.br

Recebido em 27 de maio de 2013

Aprovado em 22 de 30 de julho de 2013 